\title{
A Comprehensive Comparison of LRYGB and LSG in Obese Patients Including the Effects on QoL, Comorbidities, Weight Loss, and Complications: a Systematic Review and Meta-Analysis
}

\author{
Zhihao $\mathrm{Hu}^{1} \cdot$ Junfeng Sun ${ }^{1} \cdot$ Ruixin $\mathrm{Li}^{1} \cdot$ Zhuoyin Wang $^{1} \cdot$ Hengxuan Ding $^{1} \cdot$ Tianyu Zhu $^{1} \cdot$ Guojun Wang $^{1}$ (D
}

Published online: 13 December 2019

(C) The Author(s) 2019

\begin{abstract}
Purpose To systematically and comprehensively evaluate the differences between laparoscopic Roux-en-Y gastric bypass (LRYGB) versus sleeve gastrectomy (LSG) in obese patients.

Methods A systematic literature search was performed in PubMed, EMBASE, Web of Science, and the Cochrane Library from inception to December 2018. The meta-analysis was performed by the RevMan 5.3 software.

Results Twenty-three articles with 7443 patients were included. In short term ( $<3$ years), LRYGB was superior to LSG in terms of improving comorbidities (T2D, odds ratio (OR) 1.93, 1.06-3.52, $P<0.05$, hypertension, OR 1.59, 1.08-2.34, $P<0.05$, dyslipidemia, OR 1.61, 1.05-2.46, $P<0.05$ ), but there were no differences in the midterm and long term. Quality of life (QoL) after bariatric surgery was included, but no differences were observed in the QoL after LRYGB or LSG (gastrointestinal quality of life index (GIQLI) and Moorehead-Ardelt quality of life questionnaire (M-A-Q), $P>0.05)$. LRYGB achieved a higher EWL\% than LSG (after 3 years, WMD 5.48, 0.13-10.84. $P<0.05$; after 5 years, WMD 4.55, 1.04-8.05, $P<0.05$ ) in long term, but no significant differences were found during 0.25 - to 2.0-year follow-up. The rate of early and late complications was much higher in LRYGB than in LSG (early complications, $\mathrm{OR}=2.11,95 \% \mathrm{CI}=1.53-2.91, P<0.001$; late complications, OR $=2.60$, 95\% CI $=1.93-3.49, P<0.001)$.

Conclusions This meta-analysis showed that LRYGB was more effective than LSG in comorbidities' resolution or improvement in short term. For weight loss, LRYGB had better long-term effects than LSG. In addition, no differences were observed in the quality of life after LRYGB or LSG. LRYGB was associated with more complications than LSG.
\end{abstract}

Keywords Laparoscopic Roux-en-Y gastric bypass $\cdot$ Laparoscopic sleeve gastrectomy $\cdot$ Three-stage analysis $\cdot$ Obesity surgery

\section{Introduction}

With its increasing prevalence, obesity has become a global public health problem over the past few decades [1]. Being

Electronic supplementary material The online version of this article (https://doi.org/10.1007/s11695-019-04306-4) contains supplementary material, which is available to authorized users.

Guojun Wang

fccwanggj@zzu.edu.cn

Junfeng Sun

sunjunfenger@126.com

Ruixin $\mathrm{Li}$

liruixin01@163.com

Zhuoyin Wang

2944438919@qq.com overweight is accepted as a risk factor for serious health issues, such as type 2 diabetes, hypertension, diseases, or even cancers [2-4]. Compared with various strategies, including medications, behavior changes, and diet therapy, bariatric
Hengxuan Ding

535251839@qq.com

Tianyu Zhu

442572695@qq.com

Department of Gastrointestinal Surgery, The First Affiliated Hospital of Zhengzhou University, NO.1 Jianshe East Road, Zhengzhou 450052, Henan, China 
surgery is still recognized as the most effective treatment for weight loss and improvements of the associated comorbidities [5-7].

Primary bariatric procedures include Roux-en-Y gastric bypass (RYGB), laparoscopic adjustable gastric banding (AGB), laparoscopic vertical banded gastroplasty (VBG), sleeve gastrectomy (SG), mini-gastric bypass/one anastomosis gastric bypass (MGB/OAGB), biliopancreatic diversion/duodenal switch (BPD/DS), and singleanastomosis duodeno-ileal bypass (SADI). Among these techniques, laparoscopic Roux-en-Y gastric bypass (LRYGB) and laparoscopic sleeve gastrectomy (LSG) have gained the most popularity. However, there is a sharp trend towards the utilization of LSG over the last decade and a decline in the use of LRYGB $[8,9]$. Some studies suggest that LSG is easier and faster to perform and potentially safer compared with LRYGB $[8,10]$, while some indicate that LRYGB is more potent than LSG [11-13].

Some meta-analyses of LRYGB versus LSG have been performed before [14-17], but obvious shortcomings remain. Of the previous studies, some lack adequate stratified analysis with respect to EWL\% and comorbidities $[14,15]$.

Here, we performed a comprehensive meta-analysis comparing LRYGB with LSG with respect to their early and late complications, and amount of weight loss at different time points after surgery, as well as the effect on comorbidities at three different terms (short term, midterm, and long term) and quality of life (presented by GIQLI and M-A-Q II).

\section{Materials and Methods}

We performed a comprehensive literature search in PubMed, EMBASE, Web of Science, and the Cochrane Library from inception to December 2018. Our search strategy included the following key terms: laparoscopic sleeve gastrectomy, LSG, SG, LRYGB, RYGB, bariatric surgery, and obesity. The reference lists of potential articles as well as the extraction data were screened manually by two independent reviewers $\mathrm{CHu}$ and Sun). Any data extraction inconsistency was assessed by a third reviewer (Li).

Inclusion criteria are as follows: (1) sample size of every group > 15 patients; (2) human study reported in English; (3) at least one of the following endpoints was included: early complications, resolution rate of comorbidities, and weight loss (performed as EWL\%); (4) patient ages ranged from 18 to 70 years old; (5) comparative studies between LRYGB and LSG. Exclusion criteria are as follows: (1) non-human studies; (2) non-laparoscopic surgery; (3) studies that only included LRYGB or LSG; (4) case reports, analyses, comments, and overviews.

\section{Definition of Endpoints}

Early complications were defined as those occurring within 30 days after surgery, while late complications occurred over 30 days. For resolution or improvement rate of comorbidities, the definitions of different terms were as follows: short term ( 1 year after surgery), midterm ( 3 years), long term ( 5 years).

\section{Data Extraction}

The following data were independently extracted from each eligible study: author, publication year, study design, sample size, overall rate of early and late complications, resolution/ improvement rate of comorbidities (T2DM, hypertension, OSA, dyslipidemia), and weight loss at every follow-up point. The extraction was completed by two reviewers (Hu and Sun).

\section{Statistical Analysis}

Review Manager for the Windows version 5.3 (The Nordic Cochrane Centre, Copenhagen, Denmark) was used for analysis. Weighted mean differences (WMD) with $95 \%$ confidence intervals $(\mathrm{CI})$ were used to analyze continuous data, while odds ratios (ORs) with 95\% CIs were used for the statistical analyses of dichotomous data. Heterogeneity was represented by I2 (low heterogeneity at values $<30 \%$, moderate heterogeneity at values $30-50 \%$, and high heterogeneity at values $>50 \%$ ). The random-effects model was used for the analysis of studies with high heterogeneity, and the fixedeffects model was used for studies with low or moderate heterogeneity.

\section{Quality and Publication Bias Assessment}

The methodological quality of the included non-RCT studies was determined by the NOS (Newcastle-Ottawa scale). When the study scored $\leq 5$, the study was assessed as low quality; when the study scored $>5$, the study was assessed as high quality and was included in our meta-analysis. The methodological quality of the included RCTs was determined using Cochrane Collaboration's tool for risk of bias. Sensitivity analyses were performed by removing individual studies from the whole set of studies and analyzing the sources of significant heterogeneity. The exclusion of these studies did not influence the results. The funnel plot was used to measure publication bias. The shape of the funnel plot did not reveal obvious asymmetry (not shown).

\section{Results}

The PRISMA flow diagram of our literature search is shown in Fig. 1. A total of 742 articles were identified from the 


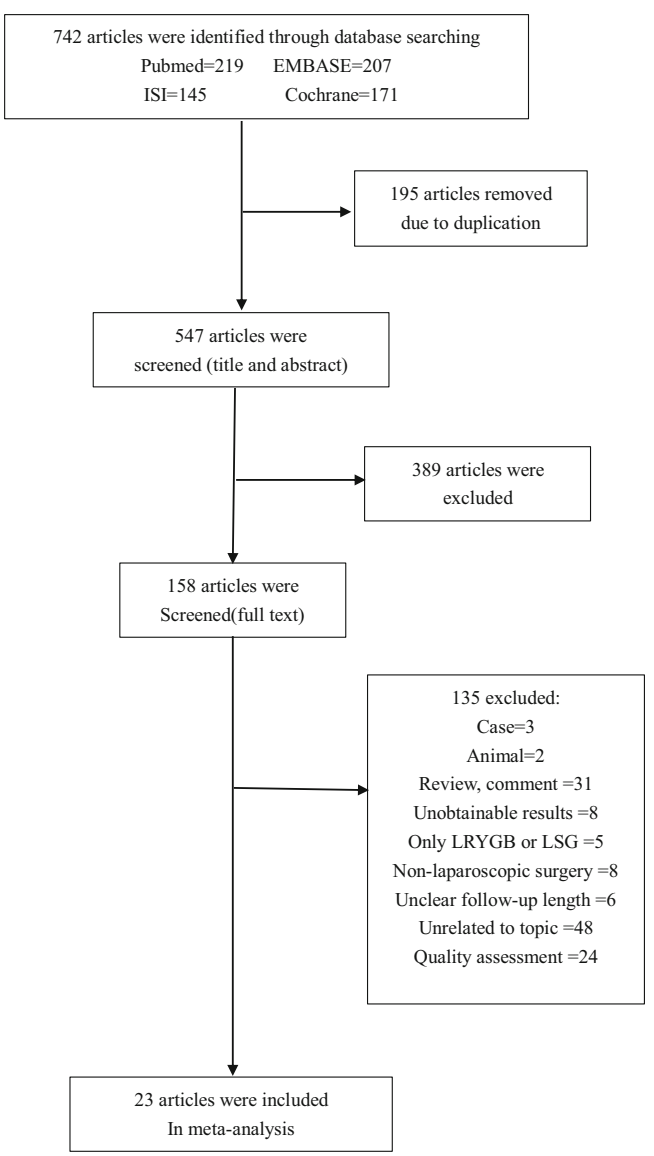

Fig. 1 PRISMA flow diagram

database, of which 719 studies were excluded after duplication, text screening, and discussion. Finally, 23 articles [18-40] were included in our analysis; 9 of them are RCTs,
5 of them are prospective studies, and 9 of them are retrospective studies. In addition, three articles [30-32] were from the same RCT but were published at different times, as well as another two articles $[34,39]$. Therefore, we combined them together in the following tables. The risk of bias for the RCTs is presented in Fig. S1. The characteristics of the included studies are shown in Table. S1.

\section{Complications}

A total of 13 studies [18-20, 22, 24, 26, 27, 30, 33, 35, 37, 39, 40] reported early complications within 30 days, of which 5 studies $[18,20,22,26,34]$ reported late complications. Overall, early complications occurred significantly more often after LRYGB than after LSG $(\mathrm{OR}=2.11,95 \% \mathrm{CI}=1.53$ $2.91, P<0.001)$. As the definitions of major or minor complications were not consistent between studies, we did not perform the analysis of major and minor complications separately. Besides, LRYGB was also associated with more late complications than LSG $(\mathrm{OR}=2.60,95 \% \mathrm{CI}=1.93-3.49$, $P<0.001)$.

All of the above data are shown in Fig. 2.

\section{Weight Loss Outcomes (EWL\%)}

Most outcomes of weight loss are measured by EWL $\% \pm \mathrm{SD}$, and we extracted data in our studies at 6 time points after surgery, including 3 months, 6 months, 1 year, 2 years, 3 years, and 5 years. There was high heterogeneity from 3 months to 3 years, and a random-effects model was applied to the analyses.
Fig. 2 Complications after surgery

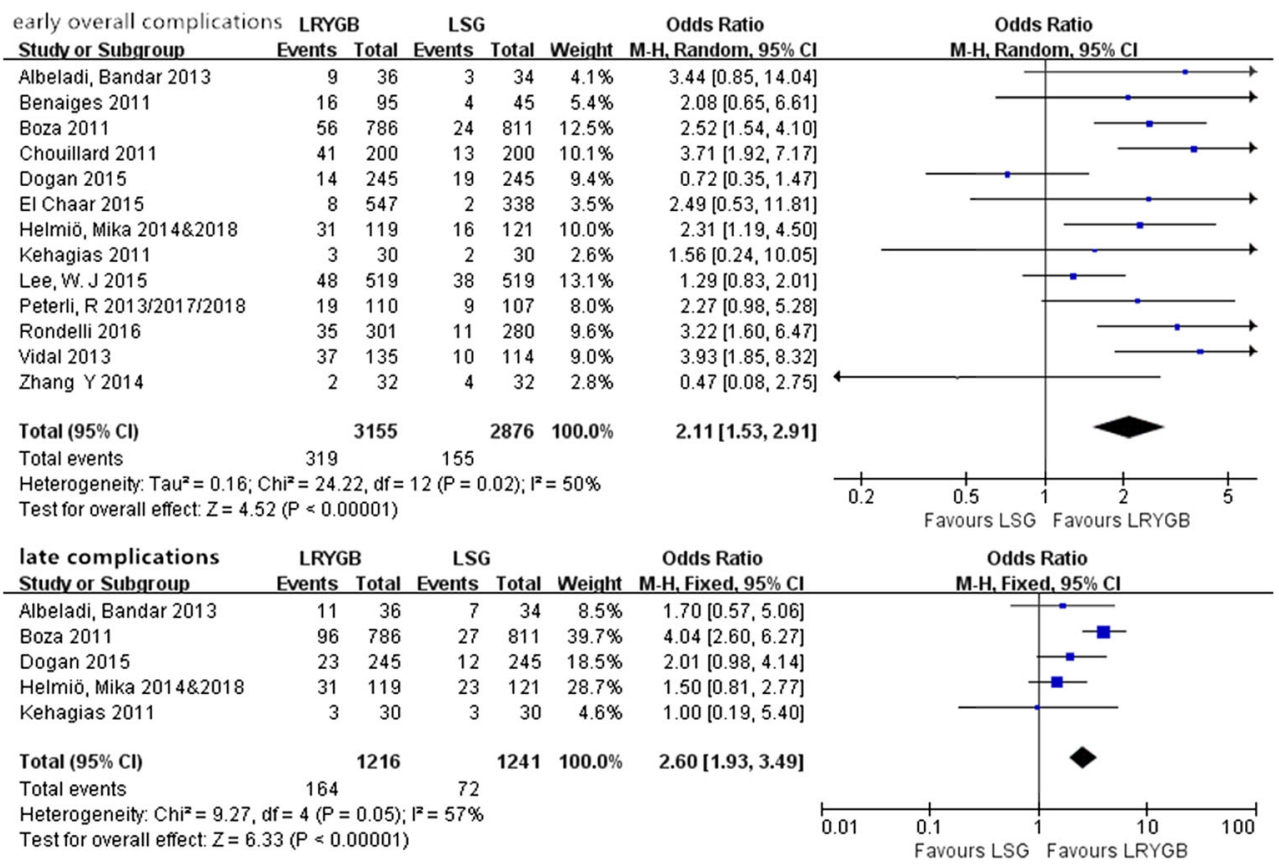


As shown in Fig. 3, there was no significant difference in the short term (from 3 months to 2 years) after surgery $(P>0.05)$. In contrast, in the midterm (after
3 years) and long term (after 5 years), LRYGB achieved a superior EWL\% compared with LSG $(P<0.01)$.
Fig. 3 EWL\% after 3 months, 6 months, 1 year, 2 years, 3 years, and 5 years

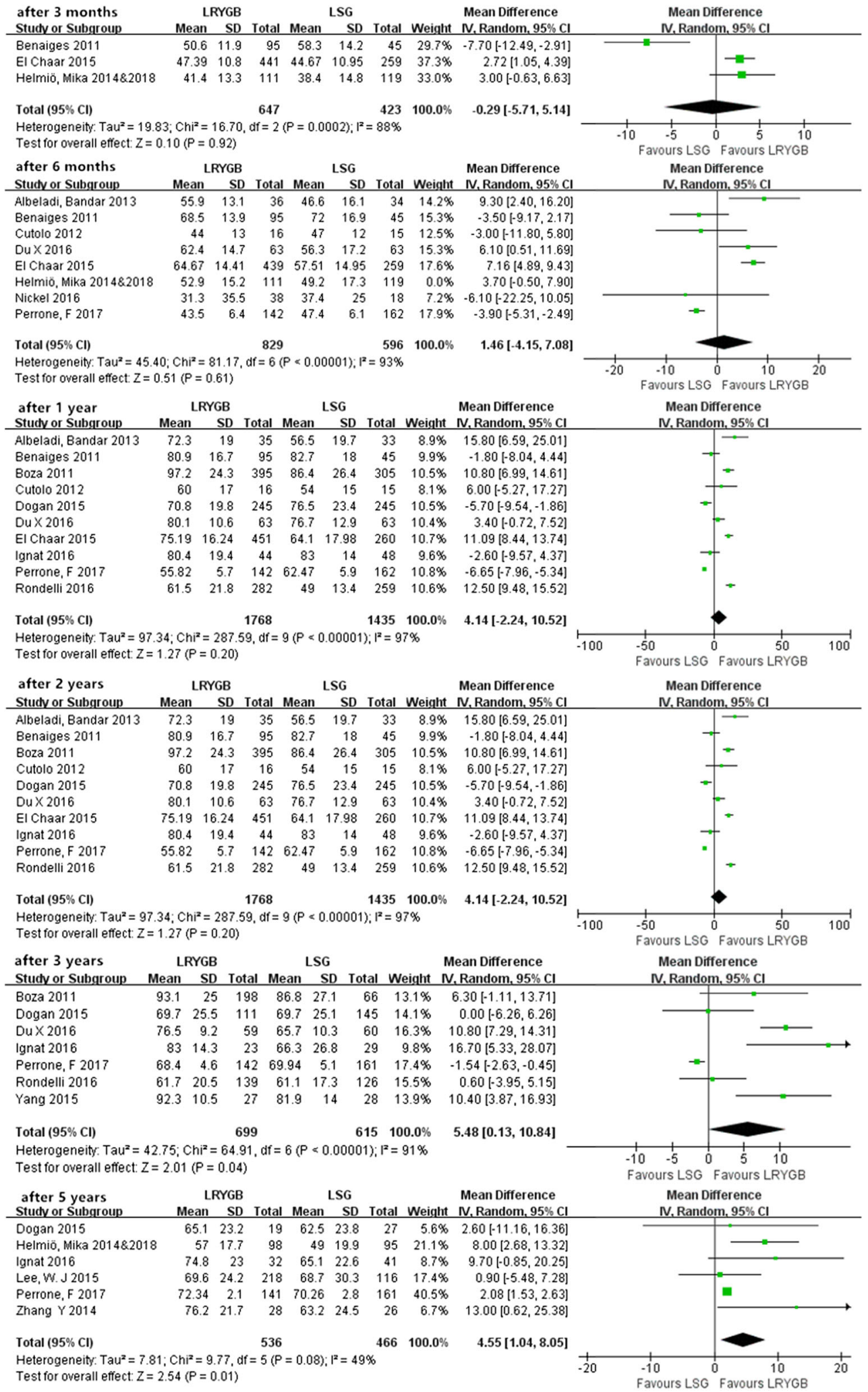




\section{Resolution/Improvement of Obesity-Related Comorbidities}

Several studies have researched the resolution/improvement rate of comorbidities. Considering that the rates of the comorbidities may differ at different times after surgery, we performed a meta-analysis at three different times.

\section{Short-Term Obesity-Related Comorbidities}

There was no remarkable heterogeneity in any of the comorbidities $(P>0.05)$, so fixed-effects models were used. Except for sleep apnea, we found that the resolution/improvement rate of T2D, hypertension, and dyslipidemia all showed significant differences between LRYGB and LSG (Fig. 4). In addition, LRYGB achieved a superior rate of resolution/ improvement for T2D, hypertension, and dyslipidemia compared with LSG.

\section{Midterm Obesity-Related Comorbidities}

As shown in (Fig. 5), there were no significant differences in any of the comorbidities mentioned.

\section{Long-Term Obesity-Related Comorbidities}

LRYGB achieved a better long-term ( $>5$ years) prognosis for hypertension after surgery than LSG with a significant difference (Fig. 6) $(\mathrm{OR}=1.98,95 \% \mathrm{CI}=1.13-3.48, P<0.05)$. The other comorbidities showed no differences between the two procedures.
Fig. 4 Short-term resolution/ improvement rate

\begin{tabular}{|c|c|c|c|c|c|c|c|c|c|c|}
\hline $\begin{array}{c}\text { T2D } \\
\text { Study or Subgroup }\end{array}$ & $\begin{array}{r}\text { LRYC } \\
\text { Events }\end{array}$ & Total & $\begin{array}{r}\text { LS } \\
\text { Events } \\
\end{array}$ & Gota & al Weigh & $\begin{array}{c}\text { Odds Ratio } \\
\text { It } \mathrm{M}-\mathrm{H} \text {. Fixed, } 95 \% \mathrm{Cl}\end{array}$ & & $\begin{array}{r}\text { Odds F } \\
\text { M-H, Fixed }\end{array}$ & $\begin{array}{l}\text { Ratio } \\
\text { d. } 95 \% \mathrm{Cl}\end{array}$ & \\
\hline Albeladi, Bandar 2013 & 6 & 7 & 1 & & $13.0 \%$ & * $1.44[0.04,56.14]$ & & & & \\
\hline Chouillard 2011 & 45 & 52 & 18 & 29 & $20.5 x$ & $3.93[1.32,11.73]$ & & & $\longrightarrow$ & \\
\hline Cutolo 2012 & 14 & 15 & 13 & 15 & $5.7 x$ & $2.15[0.17,26.67]$ & & & & \\
\hline DuX 2016 & 17 & 21 & 11 & 16 & $15.7 x$ & $1.93[0.42,8.81]$ & & & & \\
\hline Gill 2016 & 17 & 23 & 11 & 20 & $20.2 \%$ & $2.32[0.64,8.35]$ & & & & \\
\hline Helmiö, Mika $2014 \& 2018$ & 40 & 43 & 48 & 50 & $20.4 x$ & $0.56[0.09,3.49]$ & & & & \\
\hline Vidal 2013 & 36 & 39 & 23 & 24 & $14.4 x$ & $0.52[0.05,5.32]$ & & & & \\
\hline Total $(95 \% \mathrm{Cl})$ & & 200 & & 155 & $5 \quad 100.0 \%$ & $1.93[1.06,3.52]$ & & & & \\
\hline Total events & 175 & & 125 & & & & & & & \\
\hline $\begin{array}{l}\text { Heterogeneity: } \mathrm{Chi}^{2}=4.71 \text {, } \\
\text { Test for overall effect: } \mathrm{Z}=2\end{array}$ & $\begin{array}{l}d f=6(P \\
2.16(P=0\end{array}$ & $\begin{array}{l}=0.58) \text {; } \\
.03)\end{array}$ & $1^{2}=0 \%$ & & & & 0.01 & $\begin{array}{l}0.1 \\
\text { Favours LSG }\end{array}$ & $\begin{array}{c}10 \\
\text { Favours LRYGB }\end{array}$ & 100 \\
\hline $\begin{array}{l}\text { hypertension } \\
\text { Study or Subgroup }\end{array}$ & $\begin{array}{l}\text { LRYC } \\
\text { Events }\end{array}$ & Total & $\begin{array}{r}\text { LS } \\
\text { Events } \\
\end{array}$ & Gota & al Weigh & $\begin{array}{c}\text { Odds Ratio } \\
\text { It } \mathrm{M}-\mathrm{H} \text {. Fixed, } 95 \% \mathrm{Cl}\end{array}$ & & $\begin{array}{r}\text { Odds F } \\
M-H \text {, Fixed }\end{array}$ & $\begin{array}{l}\text { Ratio } \\
\text { d. } 95 \% \mathrm{Cl}\end{array}$ & \\
\hline Albeladi, Bandar 2013 & 7 & 15 & 7 & 13 & $39.9 x$ & $x_{0} \quad 0.75[0.17,3.33]$ & & $\longrightarrow$ & & \\
\hline Benaiges 2011 & 39 & 43 & 11 & 14 & $3.8 \%$ & $2.66[0.52,13.70]$ & & & & \\
\hline Chouillard 2011 & 28 & 43 & 20 & 34 & $19.2 \%$ & $1.31[0.52,3.30]$ & & & & \\
\hline Cutolo 2012 & 8 & 9 & 5 & & $1.4 x$ & $6.40[0.55,74.89]$ & & & & \\
\hline Du $\times 2016$ & 9 & 16 & 7 & 17 & $7.3 x$ & $1.84[0.46,7.31]$ & & & & \\
\hline Gill 2016 & 16 & 33 & 6 & 34 & $7.5 x$ & $4.39[1.44,13.40]$ & & & & \\
\hline Helmiö, Mika $2014 \& 2018$ & 71 & 87 & 64 & 83 & $29.7 x$ & $1.32[0.62,2.78]$ & & & & \\
\hline Vidal 2013 & 36 & 50 & 27 & 38 & $21.2 \%$ & $1.05[0.41,2.67]$ & & & & \\
\hline Total $(95 \% \mathrm{Cl})$ & & 296 & & 242 & $2100.0 \%$ & $1.59[1.08,2.34]$ & & & & \\
\hline Total events & 214 & & 147 & & & & & & & \\
\hline $\begin{array}{l}\text { Heterogeneity: } \mathrm{Chi}^{2}=7.00 \text {, } \\
\text { Test for overall effect: } \mathrm{Z}=2\end{array}$ & $\begin{array}{l}d f=7(P \\
2.36(P=0\end{array}$ & $\begin{array}{l}=0.43) ; \\
.02)\end{array}$ & $1^{2}=0 \%$ & & & & 0.01 & $\begin{array}{ll}0.1 & 1 \\
\text { Favours LSG }\end{array}$ & $\begin{array}{c}10 \\
\text { Favours LRYGB }\end{array}$ & 100 \\
\hline $\begin{array}{l}\text { dyslipidemia } \\
\text { Studv or Subgroup }\end{array}$ & $\begin{array}{l}\text { LRYG } \\
\text { Events }\end{array}$ & Total & $\begin{array}{l}\text { LSC } \\
\text { Events }\end{array}$ & Total & Weight & $\begin{array}{c}\text { Odds Ratio } \\
\text { M-H, Fixed, } 95 \% \mathrm{Cl}\end{array}$ & & $\begin{array}{r}\text { Odds } \\
\text { M-H.Fixe }\end{array}$ & $\begin{array}{l}\text { Ratio } \\
\text { d. } 95 \% \mathrm{Cl}\end{array}$ & \\
\hline Benaiges 2011 & 22 & 22 & 9 & 12 & $20.8 \%$ & $16.58[0.78,353.12]$ & & & & \\
\hline Cutolo 2012 & 1 & 2 & 3 & 5 & $2.6 \%$ & $6 \quad 0.67[0.02,18.06]$ & & & & \\
\hline Du $\times 2016$ & 21 & 33 & 21 & 36 & $21.8 \%$ & $1.25[0.47,3.30]$ & & & & \\
\hline Gill 2016 & 23 & 32 & 16 & 30 & $13.9 \%$ & $2.24[0.78,6.41]$ & & & & \\
\hline Helmiö, Mika 2014\&2018 & 31 & 45 & 25 & 39 & $24.8 \%$ & $1.24[0.50,3.08]$ & & & & \\
\hline Vidal 2013 & 54 & 79 & 33 & 57 & $36.2 \%$ & $1.57[0.77,3.19]$ & & & & \\
\hline Total $(95 \% \mathrm{Cl})$ & & 213 & & 179 & $100.0 \%$ & $1.61[1.05,2.46]$ & & & & \\
\hline Total events & 152 & & 107 & & & & & & & \\
\hline $\begin{array}{l}\text { Heterogeneity: } \mathrm{Chi}^{2}=3.46 \text {, } \\
\text { Test for overall effect: } Z=2\end{array}$ & $\begin{array}{l}d f=5(P= \\
2.19(P=0 .\end{array}$ & $\begin{array}{l}=0.63) \text {; } \\
.03)\end{array}$ & $F^{2}=0 \%$ & & & & 0.01 & $\begin{array}{l}0.1 \\
\text { Favours LSG }\end{array}$ & $1 \frac{10}{\text { Favours LRYGB }}$ & 100 \\
\hline $\begin{array}{r}\text { sleep apnea } \\
\text { Study or Subgroup }\end{array}$ & $\begin{array}{l}\text { LRYGB } \\
\text { Events }\end{array}$ & Iotal & $\begin{array}{l}\text { LSG } \\
\text { Events } \\
\end{array}$ & Iotal & Weight & $\begin{array}{c}\text { Odds Ratio } \\
\text { M-H, Fixed, } 95 \% \mathrm{Cl}\end{array}$ & & $\begin{array}{r}\text { Odds R } \\
\text { M-H. Fixed }\end{array}$ & $\begin{array}{l}\text { Ratio } \\
\text { d. } 95 \% \mathrm{Cl}\end{array}$ & \\
\hline Albeladi, Bandar 2013 & 13 & 13 & 7 & 9 & $3.6 \%$ & $9.00[0.38,213.17]$ & & & & \\
\hline Chouillard 2011 & 32 & 36 & 36 & 41 & $43.6 \%$ & $1.11[0.27,4.50]$ & & & & \\
\hline Du $\times 2016$ & 10 & 15 & 12 & 20 & $39.9 \%$ & $1.33[0.33,5.39]$ & & & & \\
\hline Vidal 2013 & 26 & 27 & 38 & 42 & $12.8 \%$ & $2.74[0.29,25.90]$ & & & & \\
\hline Total $(95 \% \mathrm{Cl})$ & & 91 & & 112 & $100.0 \%$ & $1.70[0.73,3.94]$ & & & & \\
\hline Total events & 81 & & 93 & & & & & & & \\
\hline $\begin{array}{l}\text { Heterogeneity: } \mathrm{Chi}^{2}=1.71 \\
\text { Test for overall effect: } Z=1\end{array}$ & $\begin{array}{l}1, d f=3(P \\
1.23(P=\end{array}$ & $\begin{array}{l}=0.64 \\
0.22)\end{array}$ & $4 ; 1^{2}=0 x$ & & & & 0.01 & $\begin{array}{l}0.1 \\
\text { Favours LSG }\end{array}$ & $\begin{array}{c}10 \\
\text { Favours LRYGB }\end{array}$ & 100 \\
\hline
\end{tabular}


Fig. 5 Midterm resolution/ improvement rate

Fig. 6 Long-term resolution/ improvement rate

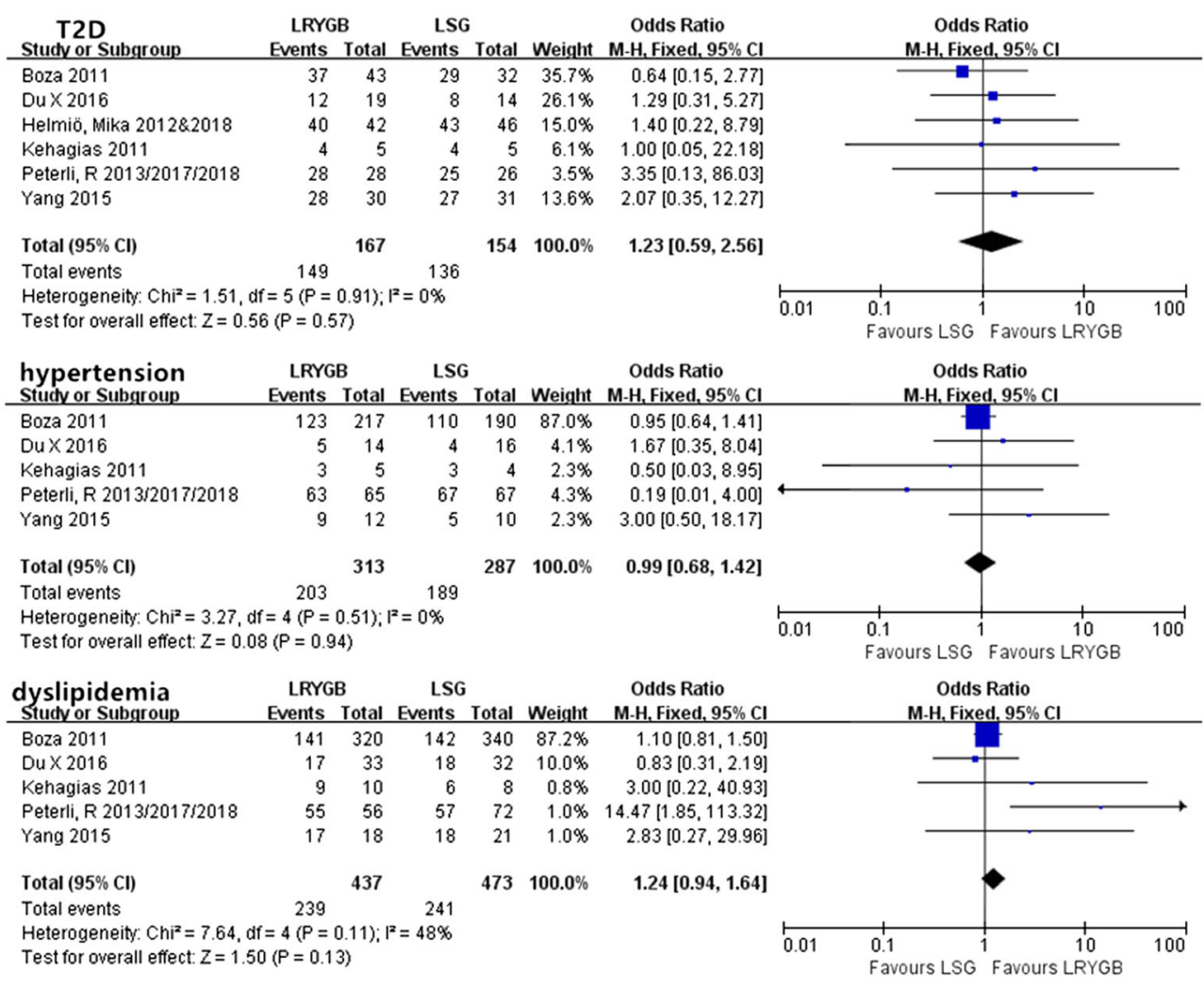

T2D LRYGB LSG Odds Ratio

Study or Subgroup Helmiö, Mika 2014\&2018 Perrone, F 2017

Peterli, R 2013/2017/2018 Zhang $Y 2014$ S Total Weight $\mathrm{M}$ - H, Fixed, 95\% Cl $\begin{array}{llllll}38 & 40 & 36 & 41 & 19.2 \% & 2.64[0.48,14.47]\end{array}$ $\begin{array}{rrrrrr}17 & 20 & 6 & 7 & 14.4 \% & 0.94[0.08,10.91] \\ 21 & 28 & 20 & 26 & 56.1 \% & 0.90[0.26,3.14]\end{array}$

Total $(95 \% \mathrm{Cl})$

Total events $\begin{array}{ll}7 & 8\end{array}$ Heterogeneity: $\mathrm{Cni}^{2}=1.11,83 \quad 70$

$3(P=0.77) ; 1^{2}=0 \%$ Test for overall effect: $Z=0.49(P=0.63)$

$83100.0 \%$ $1.24[0.52,2.94]$

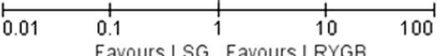

hypertension

LRYGB LSG Odds Ratio

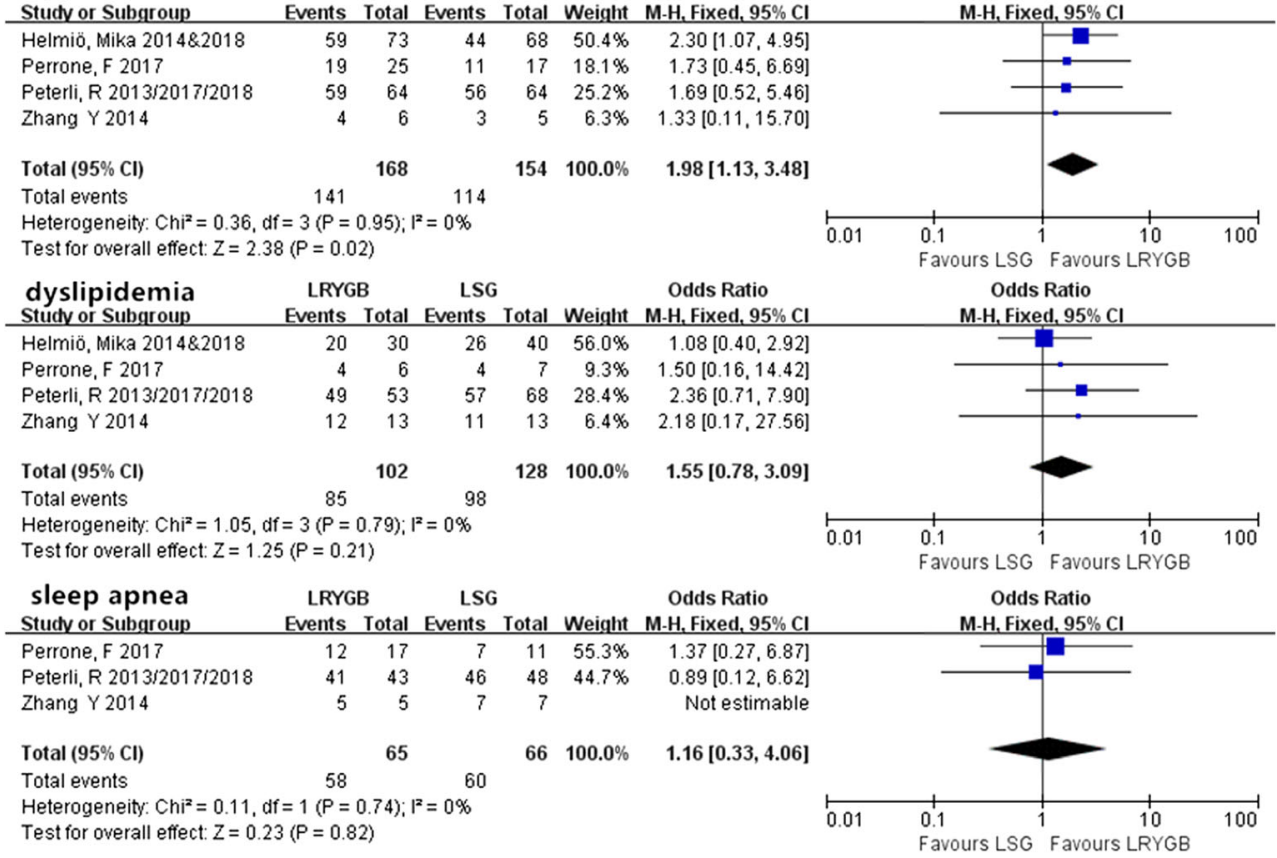




\section{Quality of Life (GIQLI and M-A-Q)}

The gastrointestinal quality of life index (GIQLI) is a questionnaire for gastrointestinal disease and includes 36 items that assess the following 5 aspects of life: core symptoms, physical items, psychological items, social items, and disease-specific items. The score of the questionnaire ranged from 0 to 144 .

The Moorehead-Ardelt quality of life questionnaire II (MA-QoL Q II) was designed to measure postoperative outcomes of self-perceived QoL in obese patients, including six parts: social relationship, self-esteem, physical activity, satisfaction concerning work, sexuality, and eating behaviors, with a total score that ranges from -3.0 to +3.0 .

For GIQLI, no significant difference was observed between the two procedures after 2 and 5 years (at 2 years, WMD = $2.19,95 \% \mathrm{CI}-1.33-5.71, P>0.05$ and at 5 years, $\mathrm{WMD}=$ $1.59,95 \% \mathrm{CI}-3-6.18, P>0.05)$. For the M-A-Q, there was also no difference between the outcomes (WMD $=0.07,95 \%$ CI $-0.14-0.29, P>0.05$ ) (Fig. 7).

\section{Discussion}

This research includes 23 studies with 3863 patients in the LSG group and 3580 patients in the LRYGB group. There have been some previous meta-analyses comparing LRYGB with LSG; however, this study is the first to systematically and comprehensively assess and compare the differences between the two surgical procedures from aspects of weight loss, rate of complications, the resolution/ improvement rate of comorbidities, and quality of life in a single article.

\section{Complications}

Regarding complications, LRYGB was significantly associated with more early complications than LSG, and the same result was observed for the late complications, which may be related to the difficulty of the LRYGB surgery. Compared with Osland's study [41], we did not perform stratified analyses as the definitions of major or minor complications were not consistent between studies.

\section{Weight Loss Outcomes}

In our research, we analyzed EWL\% at different time points after operation. Li [14] and Zhang [15] have previously analyzed the outcomes of weight loss. However, Li did not perform stratified analyses according to time points, and his conclusion is unreliable, as the weight loss differs between time points. Although Zhang performed stratified analyses, the standard of data extraction was different from ours. As a result, there were some differences in our conclusion: we found that there was no significant difference in EWL\% between the two surgical procedures during 0.25-2.0-year follow-up, but in the midterm and long term ( 3 years and 5 years, respectively), the LRYGB group had better effects than the LSG group in weight loss; this finding differs between our study and other studies. In addition, we find that the BMI in eastern country is lower than western country, which may lead to an inherent risk. But as the small number of eastern researches, a further analysis is necessary in future.

\section{Comorbidities}

In terms of comorbidities, the resolution/improvement rates differ in different periods, but previous studies from $\mathrm{Li}$ [14] and Zhang [15] did not analyze the comorbidities according to time points,

Fig. 7 Quality of life

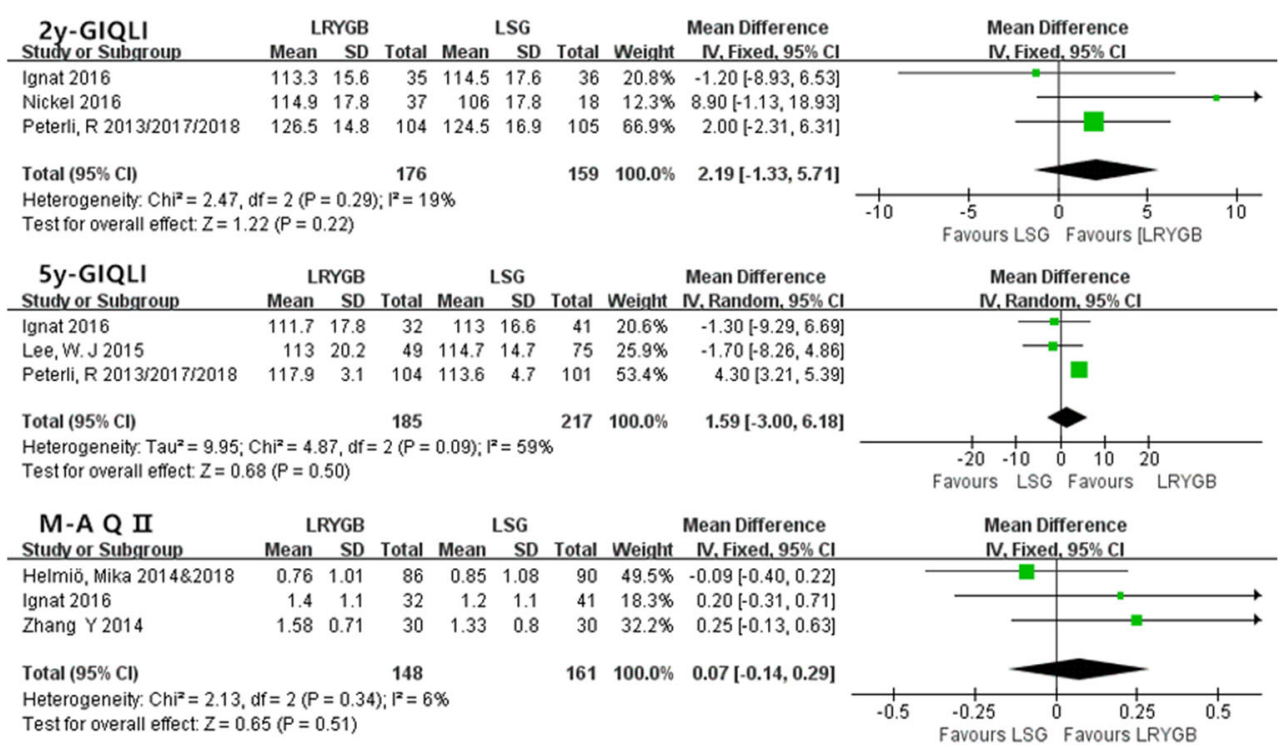


which led to the conclusion that LRYGB is better than LSG. The study from Shoar [42] included the midterm and long-term stages, but there was no short-term stage; additionally, the small number of inclusions was also mentioned as a limitation in Shoar's study. For the first time, we introduced short-term studies and analyzed the midterm and long-term results at the same time. Our results showed that in the short term, LRYGB was superior to LSG in almost all aspects (except for sleep apnea because the sample size was not large enough). After including recent studies $[29,31,34]$ of long-term follow-ups, the results showed that there were no differences between the two groups except for hypertension in the midterm and long term. Furthermore, over a longer time frame, the effect on comorbidities is equal to LSG despite better weight loss. The medical therapy may account for the result but we still need more researches.

\section{Quality of Life}

This is the first time that quality of life after these two surgeries was summarized and analyzed with a meta-analysis. With GIQLI, we studied the scores 2 years and 5 years after the operation, and the results showed no obvious differences. For M-A-Q II, there was only sufficient data in the fifth year, but there was also no difference. However, we found that Nickel's study [28] reported that the scores in the LRYGB group were significantly lower in the early period (within 6 months) than those in the LSG group. Combined with the results above, these outcomes may be related to the early complications. As LRYGB leads to more early complications, patients might focus on the difficult recovery in the early stages, but in the long term, the difference between the two groups decreases after recovery.

Our study has several limitations. Some of the included studies had a small sample size, which may affect the accuracy of this meta-analysis. Re-using a selection of 3-10 studies from the pool of 23 articles for each different research question may lead to the inherent risk of missing relevant publications for each of the individual forest plots. In terms of weight loss, the heterogeneity of analysis at each time point was high, which may be related to different race and region, and different surgical level. Besides, we only searched for English literature; therefore, language bias might exist in this research.

\section{Conclusion}

In this meta-analysis, we found that LRYGB was superior to LSG for comorbidities resolution/improvement in short term, with no difference in the midterm and long term. There was no significant difference in weight loss between LRYGB and LSG in the early period, but LRYGB showed better longterm outcomes in weight loss; in addition, no differences were observed in the quality of life after LRYGB or LSG. The rate of complications was higher for LRYGB than for LSG.
Acknowledgments Thanks Dr. Li Bingjie for the guidance in the data extraction and the use of the analysis of software in China.

Author Contributions Design of the study: Hu; collection and analysis: $\mathrm{Hu}$, Sun; discussion of conflicts: $\mathrm{Hu}$, Sun, and $\mathrm{Li}$; manuscript writing: $\mathrm{Hu}$; All authors contributed to the manuscript drafts and gave final approval for this manuscript.

Funding Information National Natural Science Foundation of China (81702343)

\section{Compliance with Ethical Standards}

Conflict of Interest The authors declare that they have no conflicts of interest.

Ethical Approval This article does not contain any studies with human participants or animals performed by any of the authors.

Informed Consent Statement Informed consent does not apply for this study.

Open Access This article is licensed under a Creative Commons Attribution 4.0 International License, which permits use, sharing, adaptation, distribution and reproduction in any medium or format, as long as you give appropriate credit to the original author(s) and the source, provide a link to the Creative Commons licence, and indicate if changes were made. The images or other third party material in this article are included in the article's Creative Commons licence, unless indicated otherwise in a credit line to the material. If material is not included in the article's Creative Commons licence and your intended use is not permitted by statutory regulation or exceeds the permitted use, you will need to obtain permission directly from the copyright holder. To view a copy of this licence, visit http://creativecommons.org/licenses/by/4.0/.

\section{References}

1. Bray GA, Frühbeck G, Ryan DH, et al. Management of obesity. Lancet. 2016;387(10031):1947-56.

2. Flegal KM, Kit BK, Orpana H, et al. Association of all-cause mortality with overweight and obesity using standard body mass index categories: a systematic review and meta-analysis. JAMA. 2013;309(1):71-82.

3. Goday A, Barneto I, García-Almeida JM, et al. Obesity as a risk factor in cancer: a national consensus of the Spanish Society for the Study of Obesity and the Spanish Society of Medical Oncology. Clin Transl Oncol. 2015;17(10):763-71.

4. Pi-Sunyer X. The medical risks of obesity. Postgrad Med. 2009;121(6):21-33.

5. Schauer PR, Bhatt DL, Kirwan JP, et al. Bariatric surgery versus intensive medical therapy for diabetes-5-year outcomes. N Engl J Med. 2017;376(7):641-51.

6. Sjostrom L et al. Lifestyle, diabetes, and cardiovascular risk factors 10 years after bariatric surgery. N Engl J Med. 2004;351(26):2683-93.

7. Sjostrom L et al. Bariatric surgery and long-term cardiovascular events. JAMA J Am Med Assoc. 2012;307(1):56-65.

8. Arafat M, Norain A, Burjonrappa S. Characterizing bariatric surgery utilization and complication rates in the adolescent population. J Pediatr Surg. 2018;

9. Angrisani L, Santonicola A, Iovino P, et al. Bariatric surgery and endoluminal procedures: IFSO worldwide survey 2014. Obes Surg. 2017;27(9):2279-89. 
10. Hutter MM et al. First report from the American College of Surgeons Bariatric Surgery Center Network: laparoscopic sleeve gastrectomy has morbidity and effectiveness positioned between the band and the bypass. Ann Surg. 2011;254(3):410-22.

11. Leyba JL, Llopis SN, Aulestia SN. Laparoscopic Roux-en-Y gastric bypass versus laparoscopic sleeve Gastrectomy for the treatment of morbid obesity. A prospective study with 5 years of follow-up. Obes Surg. 2014;24(12):2094-8.

12. Lim DM, Taller J, Bertucci W, et al. Comparison of laparoscopic sleeve gastrectomy to laparoscopic Roux-en-Y gastric bypass for morbid obesity in a military institution. Surg Obes Relat Dis. 2014;10(2):269-76.

13. Lynn W, Ilczyszyn A, Rasheed S, et al. Laparoscopic Roux-en-Y gastric bypass is as safe as laparoscopic sleeve gastrectomy. Results of a comparative cohort study. Ann Med Surg. 2018;35:38-43.

14. Li J, Lai D, Wu D. Laparoscopic Roux-en-Y gastric bypass versus laparoscopic sleeve Gastrectomy to treat morbid obesity-related comorbidities: a systematic review and meta-analysis. Obes Surg. 2016;26(2):429-42.

15. Zhang Y, Wang J, Sun X, et al. Laparoscopic sleeve gastrectomy versus laparoscopic Roux-en-Y gastric bypass for morbid obesity and related comorbidities: a meta-analysis of 21 studies. Obes Surg. 2015;25(1):19-26.

16. Yang $\mathrm{XC}$ et al. A meta-analysis: to compare the clinical results between gastric bypass and sleeve gastrectomy for the obese patients. Obes Surg. 2013;23(7):1001-10.

17. Li P, Fu P, Chen J, et al. Laparoscopic Roux-en-Y gastric bypass vs. laparoscopic sleeve gastrectomy for morbid obesity and diabetes mellitus: a meta-analysis of sixteen recent studies. HepatoGastroenterology. 2013;60(121):132-U320.

18. Albeladi B, Bourbao-Tournois C, Huten N. Short- and midterm results between laparoscopic Roux-en-Y gastric bypass and laparoscopic sleeve gastrectomy for the treatment of morbid obesity. J Obes. 2013;2013:934653.

19. Benaiges D, Goday A, Ramon JM, et al. Laparoscopic sleeve gastrectomy and laparoscopic gastric bypass are equally effective for reduction of cardiovascular risk in severely obese patients at one year of follow-up. Surg Obes Relat Dis. 2011;7(5):575-80.

20. Boza C, Gamboa C, Salinas J, et al. Laparoscopic Roux-en-Y gastric bypass versus laparoscopic sleeve gastrectomy: a case-control study and 3 years of follow-up. Surg Obes Relat Dis. 2012;8(3):243-9.

21. Cutolo PP, Nosso G, Vitolo G, et al. Clinical efficacy of laparoscopic sleeve gastrectomy vs laparoscopic gastric bypass in obese type 2 diabetic patients: a retrospective comparison. Obes Surg. 2012;22(10):1535-9.

22. Dogan K, Gadiot RP, Aarts EO, et al. Effectiveness and safety of sleeve gastrectomy, gastric bypass, and adjustable gastric banding in morbidly obese patients: a multicenter, retrospective, matched cohort study. Obes Surg. 2015;25(7):1110-8.

23. Du X et al. Laparoscopic sleeve gastrectomy versus Roux-en-Y gastric bypass for morbid obesity: a 1:1 matched cohort study in a Chinese population. Oncotarget. 2016;7(46):76308-15.

24. El Chaar M et al. Laparoscopic sleeve gastrectomy versus laparoscopic Roux-en-Y gastric bypass: a single center experience with 2 years follow-up. Obes Surg. 2015;25(2):254-62.

25. Ignat M, Vix M, Imad I, et al. Randomized trial of Roux-en-Y gastric bypass versus sleeve gastrectomy in achieving excess weight loss. Br J Surg. 2017;104(3):248-56.

26. Kehagias I, Karamanakos SN, Argentou M, et al. Randomized clinical trial of laparoscopic Roux-en-Y gastric bypass versus laparoscopic sleeve gastrectomy for the management of patients with BMI $<50 \mathrm{~kg} / \mathrm{m}(2)$. Obes Surg. 2011;21(11):1650-6.

27. Lee WJ, Pok EH, Almulaifi A, et al. Medium-term results of laparoscopic sleeve gastrectomy: a matched comparison with gastric bypass. Obes Surg. 2015;25(8):1431-8.
28. Nickel F, Schmidt L, Bruckner T, et al. Gastrointestinal quality of life improves significantly after sleeve gastrectomy and Roux-en-Y gastric bypass - a prospective cross-sectional study within a 2-year follow-up. Obes Surg. 2017;27(5):1292-7.

29. Perrone F, Bianciardi E, Ippoliti S, et al. Long-term effects of laparoscopic sleeve gastrectomy versus Roux-en-Y gastric bypass for the treatment of morbid obesity: a monocentric prospective study with minimum follow-up of 5 years. Updat Surg. 2017;69(1):101-7.

30. Peterli R, Borbély Y, Kern B, et al. Early results of the Swiss Multicentre Bypass or Sleeve Study (SM-BOSS) a prospective randomized trial comparing laparoscopic sleeve gastrectomy and Roux-en-Y gastric bypass. Ann Surg. 2013;258(5):690-5.

31. Peterli R, Wölnerhanssen BK, Peters T, et al. Effect of laparoscopic sleeve gastrectomy vs laparoscopic Roux-en-Y gastric bypass on weight loss in patients with morbid obesity the SM-BOSS randomized clinical trial. JAMA J Am Med Assoc. 2018;319(3):255-65.

32. Peterli R, Wölnerhanssen BK, Vetter D, et al. Laparoscopic sleeve gastrectomy versus Roux-Y-gastric bypass for morbid obesity-3-year outcomes of the prospective randomized Swiss Multicenter Bypass or Sleeve Study (SM-BOSS). Ann Surg. 2017;265(3):466-73.

33. Rondelli F, Bugiantella W, Vedovati MC, et al. Laparoscopic gastric bypass versus laparoscopic sleeve gastrectomy: a retrospective multicenter comparison between early and long-term post-operative outcomes. Int J Surg. 2017;37:36-41.

34. Salminen P, Helmiö M, Ovaska J, et al. Effect of laparoscopic sleeve gastrectomy vs laparoscopic Roux-en-Y gastric bypass on weight loss at 5 years among patients with morbid obesity the SLEEVEPASS randomized clinical trial. JAMA J Am Med Assoc. 2018;319(3):241-54.

35. Vidal P, Ramón JM, Goday A, et al. Laparoscopic gastric bypass versus laparoscopic sleeve gastrectomy as a definitive surgical procedure for morbid obesity. Mid-term results. Obes Surg. 2013;23(3):292-9.

36. Yang J et al. Long-term effects of laparoscopic sleeve gastrectomy versus Roux-en-Y gastric bypass for the treatment of Chinese type 2 diabetes mellitus patients with body mass index $28-35 \mathrm{~kg} / \mathrm{m}(2)$. BMC Surg. 2015;15:88.

37. Zhang Y, Zhao H, Cao Z, et al. A randomized clinical trial of laparoscopic Roux-en-Y gastric bypass and sleeve gastrectomy for the treatment of morbid obesity in China: a 5-year outcome. Obes Surg. 2014;24(10):1617-24.

38. Gill RS, Majumdar SR, Rueda-Clausen CF, et al. Comparative effectiveness and safety of gastric bypass, sleeve gastrectomy and adjustable gastric banding in a population-based bariatric program: prospective cohort study. Can J Surg. 2016;59(4):233-41.

39. Helmio M et al. Comparison of short-term outcome of laparoscopic sleeve gastrectomy and gastric bypass in the treatment of morbid obesity: a prospective randomized controlled multicenter SLEEVEPASS study with 6-month follow-up. Scand J Surg. 2014;103(3):175-81.

40. Chouillard EK, Karaa A, Elkhoury M, et al. Laparoscopic Roux-enY gastric bypass versus laparoscopic sleeve gastrectomy for morbid obesity: case-control study. Surg Obes Relat Dis. 2011;7(4):500-5.

41. Osland E, Yunus RM, Khan S, et al. Postoperative early major and minor complications in laparoscopic vertical sleeve gastrectomy (LVSG) versus laparoscopic Roux-en-Y gastric bypass (LRYGB) procedures: a meta-analysis and systematic review. Obes Surg. 2016;26(10):2273-84.

42. Shoar S, Saber AA. Long-teen and midterm outcomes of laparoscopic sleeve gastrectomy versus Roux-en-Y gastric bypass: a systematic review and meta-analysis of comparative studies. Surg Obes Relat Dis. 2017;13(2):170-80.

Publisher's Note Springer Nature remains neutral with regard to jurisdictional claims in published maps and institutional affiliations. 